\title{
Faktor Situasional dan Demografis sebagai Prediktor Niat Individu untuk Melakukan Whistleblowing
}

\author{
Tito IM. Rahman Hakim ${ }^{\text {a }}$, Bambang Subroto ${ }^{\text {a }}$, Wuryan Andayani ${ }^{\text {a }}$ \\ ${ }^{a}$ Universitas Brawijaya, Malang, Jawa Timur, Indonesia
}

INFORMASI ARTIKEL

\section{Article history:}

Dikirim tanggal: 29 Mei 2017

Revisi pertama tanggal: 30 Juni 2017

Diterima tanggal: 2 Juli 2017

Tersedia online tanggal: 17 September 2017

Keywords: situational factors, demographic factor, whistleblowing intentions, Pratama tax office

\section{ABSTRACT}

The purpose of this research is to examine and to provide empirical evidence about influence of seriousness of wrongdoing, status of wrongdoer and culture orientation on whistleblowing intentions. Respondents of this study are employees in one of Pratama tax office in Malang region. The sampling technique used is convenience sampling. It uses survey method to examine 67 employees in Pratama tax office with the help of Structural Equation Modeling-Partial Least Squares (SEM-PLS). The results show that seriousness of wrongdoing and culture orientation (collectivism) positively influence whistleblowing intentions. This research also provide empirical evidence that status of wrongdoer doesn't have significant effect on individual whistleblowing intentions

\begin{abstract}
ABSTRAK
Penelitian ini bertujuan untuk menguji dan memberikan bukti empiris pengaruh keseriusan pelanggaran, status pelanggar dan orientasi budaya terhadap niat melakukan whistleblowing. Responden penelitian ini merupakan pegawai pada salah satu Kantor Pelayanan Pajak (KPP) Pratama di wilayah Malang. Teknik pengambilan sampel yang digunakan adalah convenience sampling. Penelitian ini menggunakan metode survei untuk menguji 67 pegawai pada KPP Pratama dengan bantuan alat analisis Structural Equation Modeling-Partial Least Squares (SEMPLS). Hasil penelitian menunjukkan bahwa keseriusan pelanggaran dan orientasi budaya (kolektivisme) berpengaruh secara positif terhadap niat melakukan whistleblowing. Penelitian ini juga memberikan bukti empiris bahwa status pelanggar tidak memengaruhi niat individu untuk melakukan whistleblowing.
\end{abstract}

\section{Pendahuluan}

Korupsi masih menjadi salah satu permasalahan global di berbagai negara. Dalam hal ini sistem whistleblowing menjadi salah satu solusi dari banyaknya kasus-kasus kecurangan seperti korupsi. Sistem ini mendapatkan perhatian yang semakin intens setelah diterbitkannya SOX Act (2002) dengan anggapan bahwa sistem ini lebih mampu mendeteksi fraud dibandingkan pengendalian internal dan audit internal (Gao, Greenberg dan Wong-On-Wing, 2015). Indonesia merupakan salah satu dari banyak negara yang turut menerapkan sistem whistleblowing. Mayoritas instansi di Indonesia juga sudah menerapkan sistem ini ke dalam sistem pengendalian internalnya, namun masih sedikit individu yang bersedia menjadi whistleblower. Terkait dengan implementasinya, sistem ini dinilai kurang optimal, padahal Indonesia merupakan negara dengan tingkat korupsi yang tinggi. Hal ini didukung oleh hasil survei

* Corresponding author. Tel.: +62-857-3374-4880; e-mail: totihikam@gmail.com 
lembaga antikorupsi internasional dan nasional serta data korupsi sektor publik di Indonesia.

Survei yang dilakukan oleh sebuah lembaga antikorupsi internasional yang secara berkala setiap setahun sekali (annual) melakukan observasi atas indeks persepsi korupsi (Corruption Perception Index/CPI) pada sebuah Negara, mendukung pernyataan sebelumnya. Terlihat dari nilai CPI yang dirilis oleh Transparency International, pada tahun 2004 skor Indonesia hanyalah 20 dan baru pada tahun 2013 dan 2014 menginjak skor 34 yang masih berada dalam kategori cukup koruptif (Transparency International, 2014). Indonesia menempati peringkat 107 dari 175 negara yang disurvei. Meskipun ini hanya merupakan indeks persepsi korupsi pada suatu negara, hasil ini memperlihatkan bahwa Indonesia masih lekat dengan imaji negara koruptif.

Hasil survei integritas nasional yang dilakukan oleh KPK (Komisi Pemberantasan Korupsi) pada tahun 2009 yang hanya mencapai angka 6,50, masih dinilai rendah oleh KPK sendiri (Irianto, Novianti, Rosalina dan Firmanto, 2012). Irianto et al. (2012) juga mengemukakan bahwa terdapat 147 kepala daerah yang terlibat kasus korupsi selama tahun 2004 hingga 2010. Kasus korupsi tersebut melibatkan banyak kepala instansi daerah seperti gubernur, wakil gubernur, bupati, walikota, wakil bupati dan wakil walikota. Kerugian yang dialami atas kasus korupsi ini diperkirakan berkisar 4,4 triliun rupiah. Pemaparan data sebelumnya mempertegas lemahnya sistem pengendalian internal di Indonesia yang memicu munculnya celah yang besar untuk melakukan fraud atau wrongdoing.

Association of Certified Fraud Examiners dalam dokumentasi tentang "The Cost of Fraud" menyebutkan bahwa besarnya pendapatan sebuah perusahaan yang hilang secara global akibat fraud adalah sebesar 5\% dari pendapatan agregat perusahaan tersebut, jika dikuantifikasikan nilainya berkisar 3 miliar dolar. Angka tersebut berasal dari 1.483 kasus fraud di tempat kerja yang merupakan gabungan dari tindakan fraud seperti penyelewengan aset, korupsi dan kecurangan pada laporan keuangan (ACFE, 2014b). Pada laporan yang lebih komprehensif yaitu "Report to The Nation on Occupational Fraud and Abuse", ACFE melaporkan bahwa dari 1.483 kasus fraud di seluruh dunia pada tahun 2014, terdapat 19 kasus fraud yang berasal dari Indonesia di dalamnya (ACFE, 2014a).

Walaupun fraud atau wrongdoing dilakukan oleh individu atau kelompok kecil pada sebuah organisasi, tidak mungkin bagi individu atau kelompok lain yang tidak terlibat dalam hal tersebut untuk tidak mengetahui terjadinya kecurangan. Catatan dari Komite Nasional Kebijakan Governance (KNKG) mendukung pernyataan di atas, di mana adopsi sistem whistleblowing dipicu oleh hasil survei Institute of Bussiness Ethics (2007). Survei tersebut menyatakan satu di antara empat karyawan mengetahui adanya pelanggaran, tetapi lebih dari separuh (52\%) yang mengetahui hal ini memilih untuk menutup mulut dan tidak melakukan apapun (Semendawai et al., 2011:70).

Teori perilaku prososial (prosocial behavior theory) menyatakan bahwa walaupun seseorang mengetahui adanya suatu fraud atau wrongdoing tidak berarti mereka akan melakukan whistleblowing. Hal ini dikarenakan teori ini didasari atas tindakan prososial bukan altruistik, sehingga hanya sejumlah individu dengan karakter kepribadian tertentu (Dozier dan Miceli, 1985) dan dengan kondisi atau situasi tertentu (Miceli dan Near, 1988) yang akan melakukan whistleblowing. Implikasinya banyak penelitian mengenai whistleblowing (seperti, Ahmad, 2011; Dozier dan Miceli, 1985; MacNab dan Worthley, 2008; Mesmer-Magnus dan Viswesvaran, 2005; Miceli dan Near, 1988; ReckersSauciuc dan Lowe, 2010; Septianti, 2013; Taylor dan Curtis, 2010; Zhang, Chiu dan Wei, 2009) menggunakan teori ini sebagai landasan teoritisnya untuk menjelaskan niat individu untuk melakukan whistleblowing.

Variabel yang mengacu pada aspek situasional dan karakteristik kepribadian (demografis) individu menjadi variabel yang seringkali diteliti pada penelitian whistleblowing dengan mengacu pada teori perilaku prososial. Keseriusan pelanggaran (Near, Rehg, Scotter dan Miceli, 2004) dan status pelanggar (Mesmer-Magnus dan Viswesvaran, 2005) merupakan variabel faktor situasional yang banyak diteliti dalam penelitian whistleblowing. Dua variabel ini dianggap sebagai aspek yang sangat dipertimbangkan bagi calon whistleblower untuk melakukan whistleblowing. Variabel demografis terutama yang berhubungan dengan orientasi budaya merupakan variabel yang paling inkonsisten hasil penelitiannya (Keenan, 2002b; Keenan, 2007; MacNab et al., 2007; Nayir dan Herzig, 2012; Park, Rehg dan Lee, 2005; Park, Blenkinsopp, Oktem dan Omurgonulsen, 2008; Trongmateerut dan Sweeney, 2013). Inkonsistensi hasil penelitian whistleblowing mengenai orientasi budaya cenderung disebabkan oleh varians subjek dalam studinya. Peneliti karenanya tertarik untuk meneliti kembali ketiga variabel tersebut dengan setting penelitian yang berbeda.

Setting yang berbeda ini mengacu pada objek dan responden penelitian yang diteliti. Data dari Transparency International dan hasil survei integritas nasional yang dilakukan oleh KPK merupakan hasil survei yang dilakukan pada Instansi Sektor Publik di Indonesia. Data tersebut juga menyebutkan bahwa Instansi Sektor Publik di Indonesia identik dengan korupsi dan lekat dengan imaji koruptif. Peneliti karenanya melakukan penelitian ini pada salah satu instansi sektor publik yang bergerak pada bidang keuangan dan memiliki peranan yang sangat besar di Indonesia, yaitu Direktorat Jenderal Pajak (DJP). 
Direktorat Jenderal pajak dipilih karena instansi ini merupakan instansi pertama dibawah Kementerian Keuangan yang menerapkan sistem whistleblowing. Instansi ini memiliki reputasi yang cukup buruk di mata masyarakat karena terdapat beberapa pegawainya yang terlibat kasus fraud atau wrongdoing. Direktorat Jenderal Pajak juga telah melakukan reformasi birokrasi sejak tahun 2008 dengan tujuan untuk menciptakan iklim operasional yang lebih transparan dan akuntabel. Implikasinya sistem whistleblowing dapat menjadi salah satu media yang penting untuk mengurangi stigma negatif tersebut.

Sistem whistleblowing yang ada pada Direktorat Jenderal Pajak telah diterapkan sejak tahun 2012 (Laporan Tahunan DJP, 2015) dan merupakan pilot project pada Kementerian Keuangan. Sistem whistleblowing yang diterapkan di instansi ini juga kemudian diimplementasikan pada Kementerian Keuangan dan seluruh instansi di bawahnya. Data pengaduan selama tahun 2015 yang dipaparkan pada Laporan Tahunan DJP (2015) mengalami penurunan dari tahun sebelumnya sebesar $27,19 \%$ jika dibandingkan dengan tahun 2014.

Tidak diketahui apakah penurunan ini disebabkan oleh semakin baiknya pengendalian internal pada DJP ataukah para calon whistleblower di DJP memilih untuk diam walaupun mengetahui terjadinya fraud atau wrongdoing, yang jelas sistem whistleblowing yang diimplementasikan di DJP masih menyisakan beberapa pertanyaan, yaitu: (1) masih ambigunya tingkat kevalidan dan kecukupan bukti yang diharuskan sistem ini, (2) seberapa besar jaminan keamanan yang diberikan DJP kepada whistleblower, dan (3) seberapa independen tim investigator yang ditugaskan untuk mengkaji bukti adanya fraud dan wrongdoing. Penelitian ini akan difokuskan pada salah satu KPP Pratama berprestasi yang berada pada wilayah Kanwil DJP Jatim III yang merupakan satu-satunya Kanwil di Indonesia yang kinerjanya naik di tahun 2016 dibandingkan tahun sebelumnya.

\section{Teori}

\subsection{Teori Perilaku Prososial (Prosocial Behavior Theory)}

Perilaku prososial mengacu pada tindakan sukarela yang ditujukan untuk membantu atau menguntungkan orang atau kelompok lain (Eisenberg dan Mussen, 1989:3). Brief dan Motowidlo (1986) mendefinisikan perilaku prososial dalam lingkup organisasional sebagai perilaku yang ditampilkan oleh anggota organisasi yang ditujukan langsung kepada individual, kelompok, atau organisasi yang di dalamnya dia berinteraksi dengan membawa peran organisasionalnya dan dilakukan dengan tujuan menguntungkan individual, kelompok, atau organisasi tersebut. Studi mengenai whistleblowing kebanyakan menggunakan teori perilaku prososial (prosocial behavior theory) sebagai dasar teoritisnya.

\subsection{Niat Melakukan Whistleblowing}

Whistleblowing system merupakan salah satu mekanisme untuk menilai akuntabilitas organisasi publik dan privat (Septianti, 2013). Near dan Miceli (1985) mendefinisikan whistleblowing sebagai pengungkapan yang dilakukan oleh karyawan atau mantan karyawan organisasi atas suatu praktik ilegal, tidak bermoral, atau tanpa legitimasi hukum di bawah kendali pimpinan mereka kepada individu atau organisasi yang dapat menimbulkan efek tindakan perbaikan. Penelitian whistleblowing cenderung mengobservasi niat dibandingkan tindakan aktual whistleblowing karena lebih mudah diamati. Niat melakukan whistleblowing didefinisikan sebagai kecenderungan seseorang untuk benar-benar terlibat langsung dalam tindakan whistleblowing (Chiu, 2002).

\subsection{Keseriusan Pelanggaran}

Graham (1986) dalam Zhuang (2003) menyebutkan definisi keseriusan sebagai, "sejauh mana sebuah permasalahan mengenai etika yang dilihat secara serius merupakan sebuah fungsi dari karakteristik-karakteristik objektif atas situasi, penilaian nyata dari orang lain mengenai keseriusan suatu hal dan tendesi individu manapun untuk melebih-lebihkan atau menyepelekan peliknya suatu masalah. Keseriusan pelanggaran dalam hal ini lebih mengacu kepada dampak yang diberikan kepada organisasi dan masyarakat atas tindak fraud atau wrongdoing yang dilakukan oleh individu. Semakin besar dampak yang ditimbulkan, semakin besar pula kecenderungan individu untuk mengambil tindakan etis guna memitigasi efek negatif tersebut.

\subsection{Status Pelanggar}

Status pelanggar merupakan salah satu dimensi situasional yang erat kaitannya dengan konsep kekuasaan (power). Konsep kekuasaan ini memberikan rasionalisasi atas hierarki kekuatan yang dimiliki individu pada suatu organisasi. Semakin tinggi hierarki yang dimiliki individu pada sebuah organisasi semakin ajeg pula posisinya dalam menekan tindakan negatif yang akan merugikannya (Ahmad, 2011). Sehubungan dengan tindakan etis yang diambil oleh seseorang untuk menghalangi atau memitigasi fraud atau wrongdoing, status pelanggar merupakan faktor penting yang harus diperhatikan secara seksama. Perhitungan ini meliputi perbandingan dan sejauh mana rentang hierarki atau jabatan yang ada antara pelapor (whistleblower) dan individu yang akan dilaporkan. 


\subsection{Orientasi Budaya}

Orientasi budaya merupakan sebuah faktor unik yang seringkali diteliti dalam hal tindakan etis dan whistleblowing (Keenan, 2002a; Keenan, 2007; Nayir dan Herzig, 2012; Trongmateerut dan Sweeney, 2013). Hal ini dikarenakan letak demografis seperti negara, suku dan ada istiadat merupakan salah satu faktor eksternal yang cenderung memengaruhi gaya berpikir dan bertindak individu. Park et al. (2008) menyatakan bahwa budaya memiliki peran untuk membentuk persepsi individu mengenai hal-hal penting (key issues). Hal penting ini juga menyangkut keputusan individu untuk terlibat dalam whistleblowing atau memilih untuk diam. Indonesia sendiri merupakan negara dengan pluralitas budaya, bahasa, agama dan adat istiadat.

Hofstede (1980, 1983) dalam Gray (1988) memaparkan bahwa terdapat empat dimensi kebudayaan yang merupakan nilai budaya yang penting dalam hal implementasi suatu kebijakan ataupun sistem, yaitu individualisme, jarak kekuasaan, penolakan ketidakpastian dan maskulinitas. Keempat dimensi nilai budaya ini saling berbenturan karena terdapat dua sisi yang berlawanan sehingga membentuk sebuah keyakinan dan kepercayaan yang menjadi identitas suatu bangsa. Individualisme-kolektivisme, besar-kecil jarak kekuasaan, kuat-lemah penolakan ketidakpastian dan maskulinitas-feminisme dianggap sebagai faktor penting yang menunjukkan bahwa setiap suku bangsa memiliki keunikan sendiri yang jelas berbeda dengan bangsa yang lain yang berbeda demografis (Gray, 1988).

\subsection{Keseriusan Pelanggaran dan Niat Melakukan Whistleblowing}

Mengacu pada teori perilaku prososial yang menyatakan bahwa individu akan berusaha untuk memberikan kebermanfaatan kepada individu atau sekelompok individu lain (Brief dan Motowidlo, 1986; Eisenberg dan Mussen, 1989:3), maka calon whistleblower akan memiliki niat untuk melakukan whistleblowing jika melihat suatu fraud atau wrongdoing. Semakin besar efek yang ditimbulkan oleh suatu pelanggaran (fraud atau wrongdoing) maka semakin kuat pula insentif individu untuk melakukan pelaporan (whistleblowing) (Near et al., 2004).

Landasan teoritis ini didukung oleh banyak hasil penelitian sebelumnya seperti Ahmad (2011), Ayers dan Kaplan (2005), Cassematis dan Wortley (2013), MesmerMagnus dan Viswesvaran (2005), Miceli, Near dan Schwenk (1991), Near et al. (2004), Robinson, Robertson dan Curtis (2012), Septianti (2013) dan Winardi (2013) yang menyatakan bahwa keseriusan pelanggaran berpengaruh positif terhadap dorongan seseorang untuk melakukan whistleblowing.

Peneliti melalui fakta dan teori di atas menduga dan merumuskan hipotesis sebagai berikut:

\section{H1: Keseriusan pelanggaran berpengaruh terhadap niat melakukan whistleblowing.}

\subsection{Status Pelanggar dan Niat Melakukan Whistleblowing}

Status pelanggar merupakan salah satu dimensi situasional yang berhubungan dengan teori kekuasaan (power). Teori kekuasaan ini memberikan rasionalisasi atas hierarki kekuatan individu pada organisasi. Semakin tinggi hierarki yang dimiliki seseorang pada sebuah organisasi semakin ajeg posisinya dalam menekan tindakan negatif yang akan merugikannya (Ahmad, 2011). Teori perilaku prososial juga menjelaskan bahwa individu akan melakukan tindakan yang dirasa akan memberikan manfaat kepada pihak lain (Brief dan Motowidlo, 1986; Eisenberg dan Mussen, 1989:3), namun individu tersebut juga akan memperhitungkan konsekuensi yang mungkin akan terjadi jika ia melakukan whistleblowing (Dozier dan Miceli, 1985). Jika konsekuensi yang akan diterima oleh calon whistleblower cenderung negatif dan merugikan, dalam hal ini terdapat jarak kekuasaan yang besar antara pelapor (whistleblower) dan pelaku fraud atau wrongdoing, maka dia akan memutuskan untuk diam.

Mesmer-Magnus dan Viswesvaran (2005) melalui studinya yang menggunakan meta-analisis menampilkan bukti bahwa status pelanggar berpengaruh terhadap niat melakukan whistleblowing. Hasil penelitian ini juga didukung oleh Ahmad (2011) melalui penelitiannya yang menggunakan lima jenis vignette atau skenario/ skema singkat yang menunjukkan bahwa status pelanggar pada dua skenario berpengaruh atas niat melakukan whistleblowing oleh auditor internal di Malaysia.

Peneliti melalui fakta dan teori di atas menduga dan merumuskan hipotesis sebagai berikut:

H2: Status pelanggar berpengaruh terhadap niat melakukan whistleblowing.

\subsection{Orientasi Budaya dan Niat Melakukan Whistleblowing}

Teori perilaku prososial dalam artikel Dozier dan Miceli (1985) menyatakan bahwa individu dengan karakteristik kepribadian tertentu lebih cenderung untuk melakukan whistleblowing dibandingkan individu dengan karakteristik kepribadian lainnya. Indonesia memiliki ragam suku yang memiliki pedoman norma yang cenderung berbeda antara suku satu dengan suku yang lain. Suku Madura, ambon dan batak identik dengan temperamennya yang keras sedangkan suku jawa dan sunda sebaliknya. Septianti (2013) mengungkapkan bahwa nilai yang dibawa atas dasar suku seringkali terlihat dari performa kerja dan karakteristik individu.

Indonesia merupakan negara yang cocok untuk diteliti mengenai orientasi budaya karena keragaman dari setiap daerah yang memiliki nilai-nilai budaya yang 
berbeda. Walaupun demikian, arah pengaruh dari variabel ini tidaklah mampu ditentukan karena suku bangsa tertentu memiliki kecenderungan untuk berpengaruh positif maupun negatif atas whistleblowing. Variabel ini merupakan salah satu variabel yang memengaruhi niat individu untuk melakukan whistleblowing namun tidak diketahui arah pengaruhnya. Mengacu pada salah satu dimensi kultural Hofstede yaitu individualisme-kolektivisme, individu dengan dimensi kultural individualisme lebih cenderung melakukan whistleblowing. Pada penelitian yang menggunakan dimensi kultural Hofstede, dimensi individualismekolektivisme merupakan dimensi yang paling dominan dan paling mampu menjelaskan tindak whistleblowing. Dimensi kultural individualisme-kolektivisme merupakan proksi yang paling banyak digunakan dalam penelitian mengenai orientasi budaya (Park et al., 2008).

Peneliti melalui fakta dan teori di atas menduga dan merumuskan hipotesis sebagai berikut:

H3: Orientasi budaya berpengaruh terhadap niat melakukan whistleblowing.

\section{Metode Penelitian}

\subsection{Populasi dan Sampel}

Populasi pada penelitian ini adalah seluruh pegawai pada salah satu KPP Pratama di wilayah Malang yang berprestasi. Untuk menentukan berapa sampel yang dibutuhkan peneliti mengacu pada Sholihin dan Ratmono (2013:12) dan Hair, Hult, Ringle dan Sarstedt (2014:20) yang menyatakan jumlah sampel minimal yang menjadi syarat pada SEM-PLS adalah sebanyak sepuluh kali jumlah jalur (path). Convenience sampling merupakan teknik pengambilan sampel pada penelitian ini karena terbatasnya data yang dimiliki peneliti mengenai responden penelitian. Didapatkan sebanyak 67 kuisioner yang akhirnya siap untuk dianalisis. Tabel 1 menjelaskan sampel dan tingkat pengembalian kuisioner:

Tabel 1

Sampel dan Tingkat Pengembalian Kuisioner

\begin{tabular}{lc}
\hline \multicolumn{1}{c}{ Keterangan } & $\begin{array}{c}\text { Jumlah } \\
\text { Kuisioner }\end{array}$ \\
\hline Kuisioner yang disebar & 90 \\
Kuisioner yang tidak kembali & 14 \\
Kuisioner yang kembali & 76 \\
Kuisioner yang tidak dapat diolah & 9 \\
Kuisioner yang dapat diolah & 67 \\
\hline Tingkat pengembalian kuisioner (response & $74,44 \%$ \\
rate) =(67/90) x 100\% & \\
\hline
\end{tabular}

Sumber: Data diolah 2017

\subsection{Pengukuran Variabel}

Pengukuran variabel pada penelitian ini dilakukan dengan menggunakan instrumen berupa kuisioner dan kasus hipotetis. Variabel Keseriusan Pelanggaran (KP),
Status Pelanggar (SP), dan Niat Melakukan Whistleblowing (NMW) diukur dengan menggunakan tiga jenis kasus hipotetis yang dikembangkan oleh Septianti (2013), sedangkan variabel Orientasi Budaya (OB) diukur dengan menggunakan kuisioner yang diadopsi dari Nayir dan Herzig (2012). Responden diminta untuk memberikan skor pada kuisioner dan kasus hipotetis dengan skala Likert 1-7.

\subsection{Analisis Data}

Peneliti menggunakan warpPLS 5.0 untuk menganalisis data dalam penelitian ini. Terdapat 2 tahapan untuk menganalisis data pada penelitian ini (1) peneliti harus mengobservasi outer model penelitian sebelum, (2) menginterpretasi hasil analisis data yang tertera pada inner model. Pengujian hipotesis pada studi ini akan dilakukan dengan cara sebagai berikut, yaitu:

a) Menentukan level signifikan atau nilai kritis $(\alpha)$ yaitu sebesar 5\%; dan

b) Melihat signifikansi $p$ value dan arah koefisien. Jika signifikansi $p$ value $\leq 0,05(5 \%)$ dan arah dari koefisien sesuai dengan arah yang ditentukan pada hipotesis maka hipotesis tersebut didukung, jika sebaliknya maka hipotesis tidak didukung.

\section{Hasil Penelitian dan Pembahasan}

Melalui analisis data dengan bantuan alat statistik warpPLS 5.0, diketahui model struktural penelitian sebagai berikut:

\section{Gambar 1}

Model Struktural Pengujian Hipotesis

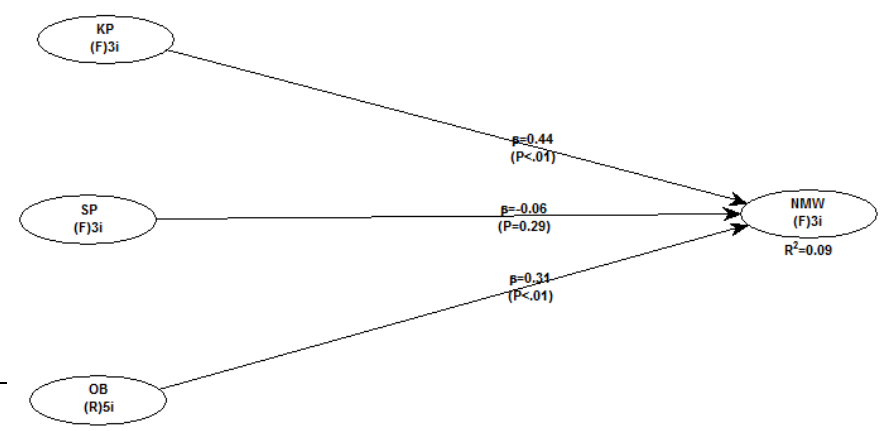

Sumber: Data Diolah 2017

Model struktural di atas terlebih dahulu diuji outer model-nya dan telah lulus uji validitas konvergen, validitas validitas diskriminan, dan reliabilitas (lihat Lampiran). Langkah selanjutnya adalah melihat inner model yang dapat dilihat pada Gambar 1. Secara keseluruhan ringkasan uji hipotesis pada penelitian ini dijelaskan pada tabel 2:

\section{Tabel 2}

Hasil Uji Hipotesis

\begin{tabular}{|c|c|c|c|c|}
\hline No. & $\begin{array}{c}\text { Notasi } \\
\text { Hipotesis }\end{array}$ & $\begin{array}{c}\text { Nilai } \\
\text { Koefisien } \\
\text { Jalur }\end{array}$ & $\begin{array}{c}\text { Nilai } p \\
\text { (two- } \\
\text { tailed })\end{array}$ & Keputusan \\
\hline 1. & $\mathrm{H} 1$ & 0,442 & $<0,001$ & Diterima \\
\hline 2. & $\mathrm{H} 2$ & $-0,065$ & 0,295 & Ditolak \\
\hline
\end{tabular}




\begin{tabular}{|c|c|c|c|c|}
\hline No. & $\begin{array}{c}\text { Notasi } \\
\text { Hipotesis }\end{array}$ & $\begin{array}{c}\text { Nilai } \\
\text { Koefisien } \\
\text { Jalur }\end{array}$ & $\begin{array}{c}\text { Nilai } p \\
(\text { two- } \\
\text { tailed })\end{array}$ & Keputusan \\
\hline 3. & H3 & 0,306 & 0,004 & Diterima \\
\hline
\end{tabular}

Sumber: Hasil analisis, 2017

\subsection{Pengaruh Keseriusan Pelanggaran Terhadap Niat Melakukan Whistleblowing}

Dari pengujian $\mathrm{H} 1$ diketahui bahwa nilai signifikansinya $(p)$ sebesar $<0,001$ yang menandakan bahwa hipotesis ini diterima. Variabel keseriusan pelanggaran (KP) terbukti secara empiris memengaruhi niat individu untuk melakukan whistleblowing. Hasil penelitian ini sejalan dengan penelitian Ahmad (2011), Ayers dan Kaplan (2005), Cassematis dan Wortley (2013), Mesmer-Magnus dan Viswesvaran (2005), Septianti (2013) dan Winardi (2013). Hal ini menunjukkan bahwa individu sangat mempertimbangkan apakah konsekuensi dari fraud atau wrongdoing yang terjadi sangatlah signifikan atau tidak sebelum memutuskan untuk melakukan whistleblowing. Pernyataan di atas sesuai dengan Near et al. (2004) yang menyatakan bahwa dorongan individu untuk melakukan whistleblowing akan semakin besar jika fraud atau wrongdoing yang terjadi memiliki dampak yang sangat besar.

Bukti empiris ini juga mendukung teori perilaku prososial yang menyatakan bahwa individu akan melakukan hal yang akan membantu publik secara luas, baik itu organisasi di mana dia bekerja ataupun individu lainnya. Individu yang mengamati suatu fraud atau wrongdoing akan terdorong untuk melakukan whistleblowing agar organisasi tempatnya bekerja ataupun individu lain di luar organisasi yang mungkin terkena imbas dari kecurangan terhindar dari hal tersebut.

\subsection{Pengaruh Status Pelanggar Terhadap Niat Melakukan Whistleblowing}

Pengujian $\mathrm{H} 2$ menunjukkan bahwa variabel status pelanggar bukan merupakan prediktor individu untuk melakukan whistleblowing. Hal ini terlihat dari nilai signifikansi $(p)$ yang lebih besar dari 0,05, yaitu 0,295. Nilai koefisien jalur dari pengujian hipotesis ini bernilai $-0,065$. Nilai negatif ini menunjukkan bahwa variabel ini memengaruhi niat melakukan whistleblowing secara negatif walaupun tidak signifikan. Hasil penelitian ini berlawanan dengan hasil penelitian Miceli et al. (1991) dan Winardi (2013) yang menemukan adanya pengaruh negatif. Temuan penelitian ini sejalan dengan penelitian Ahmad (2011), Gao et al. (2014) dan Septianti (2013).

Perbedaan hasil penelitian ini dengan penelitian sebelumnya kemungkinan disebabkan oleh responden pada penelitian ini. Responden pada penelitian ini merupakan pegawai KPP Pratama yang merupakan bagian dari Direktorat Jenderal Pajak. Terdapat tiga hal yang menurut peneliti menjadi penyebab tidak terbuktinya hipotesis 2 ini. Ketiga hal tersebut berasal dari sistem whistleblowing yang diimplementasikan pada Direktorat Jenderal Pajak, yaitu (1) anonimitas, (2) imbalan (reward), dan (3) jaminan keamanan. Peraturan Direktur Jenderal Pajak Nomor 22 Tahun 2011 mengelaborasi mengenai ketiga hal tersebut sebagai berikut:

a) Sistem whistleblowing yang ada pada Direktorat Jenderal Pajak memungkinkan whistleblower untuk menjaga kerahasian dirinya (anonim). Terdapat pula lebih dari satu saluran yang dapat digunakan oleh pegawai untuk melakukan pelaporan pelanggaran (whistleblowing), seperti email, surat tertulis kepada Direktur Jenderal Pajak, Direktur Kepatuhan Internal dan Transformasi Sumber Daya Aparatur (KITSDA), atau melalui SIKKA yang merupakan sistem yang dimiliki oleh setiap pegawai pajak. Pada saat pelaporan kepada pihak-pihak terkait pelapor (whistleblower) memang diharuskan untuk memberitahukan identitasnya, namun identitas whistleblower ini terjamin kerahasiaannya;

b) Direktorat Jenderal Pajak juga akan memberikan imbalan berupa materi dan kenaikan jabatan pada whistleblower yang laporannya terbukti. Terdapat lima imbalan (reward) yang ditawarkan bagi whistleblower, yaitu (1) promosi sampai dengan eselon IV atau usulan promosi hingga eselon II, (2) mutasi sesuai dengan keinginan whistleblower, (3) kenaikan pangkat istimewa atau luar biasa, (4) pelatihan atau short course, dan/atau (5) imbalan prestasi kerja khusus maksimal sepuluh kali besarnya Tunjangan Khusus Pengelola Keuangan Negara (TKPKN) atau imbalan lain yang setara; dan

c) Sistem whistleblowing pada Direktorat Jenderal Pajak juga menjelaskan mengenai bagaimana mekanisme perlindungan whistleblower. Terdapat dua bentuk umum dari upaya perlindungan ini, yaitu permohonan mutasi agar tidak mendapatkan retaliasi dari pihak yang dilaporkan jika whistleblower dan yang dilaporkan bertugas pada kantor yang sama atau permohonan perlindungan pada Lembaga Perlindungan Saksi dan Korban (LPSK).

Konsekuensinya tidak peduli rendah atau tingginya status jabatan pelaku fraud atau wrongdoing yang whistleblower laporkan, mereka akan tetap dapat melakukan whistleblowing dengan aman. Whistleblower pada Direktorat Jenderal Pajak karenanya tidak melihat status pelanggar sebagai sesuatu yang perlu dipertimbangkan untuk melakukan pelaporan (whistleblowing), walaupun masih tetap akan lebih aman jika whistleblower melaporkan pelanggar yang memiliki status jabatan yang lebih rendah dari dirinya. 


\subsection{Pengaruh Orientasi Budaya Terhadap Niat Melakukan Whistleblowing}

Orientasi budaya merupakan salah satu faktor yang membuat individu memiliki tendensi yang lebih besar untuk melakukan whistleblowing. Variabel ini terbukti secara empiris memengaruhi niat individu untuk melakukan whistleblowing. Hal ini terlihat dari signifikansi nilai $p$ yang dihasilkan dari pengujian $\mathrm{H}$, yaitu sebesar 0,004. Hasil penelitian ini sejalan dengan hasil penelitian sebelumnya dari Nayir dan Herzig (2012) dan Park et al. (2008). Hasil penelitian ini memang menunjukkan bukti empiris yang serupa dengan penelitian Nayir dan Herzig (2012) serta Park et al. (2008), namun dimensi orientasi budaya antara dua penelitian sebelumnya dan penelitian saat ini berbeda.

Penelitian Nayir dan Herzig (2012) serta Park et al. (2008) menunjukkan adanya pengaruh antara variabel orientasi budaya, yaitu individualisme dengan niat melakukan whistleblowing. Kedua penelitian tersebut memberikan bukti empiris bahwa individu dengan tingkat individualisme yang tinggi akan lebih cenderung untuk melakukan whistleblowing. Hal ini juga searah dengan apa yang peneliti hipotesiskan di awal, bahwa individu yang individualis merupakan individu yang akan lebih mungkin terlibat dengan whistleblowing. Penelitian ini sebaliknya memberikan bukti empiris bahwa individu dengan orientasi budaya kolektivisme yang lebih cenderung untuk terlibat dalam whistleblowing.

Temuan penelitian saat ini sangat menarik, karena MacNab et al. (2007), Nayir dan Herzig (2012), Park et al. (2005), dan Park et al. (2008) mengungkapkan dalam artikelnya bahwa individu dengan individualisme yang tinggi akan lebih independen dan karenanya memiliki kemungkinan yang lebih besar untuk melakukan whistleblowing. Individualisme juga merupakan konsep kebudayaan yang lebih identik dengan whistleblowing dibandingkan kolektivisme, sehingga telah menjadi konsensus bahwa individu yang melakukan whistleblowing merupakan individu dengan individualisme yang tinggi.

Peneliti mengacu pada teori perilaku prososial mencoba membangun kembali logika berpikir mengenai hasil penelitian yang kontras ini. Dozier dan Miceli (1985) menyatakan bahwa teori perilaku prososial merupakan teori mengenai perilaku individu yang ingin memberikan manfaat kepada masyarakat (sosial). Menurut Hofstede (1985) individualisme mengacu pada ikatan sosial yang longgar di mana individualis lebih cenderung menjaga dirinya sendiri dan keluarganya, sedangkan kolektivisme merupakan individu dengan ikatan sosial yang kuat dengan kelompok sosialnya.

Individu dengan kolektivisme yang tinggi memiliki kecenderungan yang lebih besar untuk melakukan whistleblowing dibandingkan individu dengan individualisme jika mengacu pada Dozier dan Miceli
(1985) serta Hofstede (1985). Individu dengan kolektivisme memiliki ikatan yang lebih besar dengan lingkungan sosialnya, baik itu keluarga, organisasi, dan masyarakat secara luas, karenanya mereka memiliki kemungkinan yang lebih besar untuk terlibat dalam pelaporan fraud atau wrongdoing (whistleblowing). Pernyataan di atas juga diperkuat oleh teori perilaku prososial, sehingga individu dengan kolektivisme akan memiliki niat yang lebih besar untuk melakukan whistleblowing guna mencegah dampak buruk dari fraud atau wrongdoing baik itu bagi dirinya, keluarganya, organisasi tempat ia bekerja bahkan publik secara luas.

Individu dengan individualisme yang tinggi sebaliknya, lebih cenderung memikirkan dirinya (selfcentered) dan lingkaran sosial terkecilnya, yaitu keluarga. Individu ini memiliki kecenderungan yang lebih rendah untuk melakukan whistleblowing selama dirinya dan keluarganya tidak dirugikan atas fraud atau wrongdoing yang terjadi di tempat kerjanya. Peneliti karena itu menyimpulkan bahwa individu dengan kolektivisme memiliki niat yang lebih besar untuk melakukan whistleblowing. Penelitian-penelitian selanjutnya dibutuhkan guna melihat konsistensi hasil penelitian sebelumnya serta mengkonfirmasi hasil penelitian saat ini.

\section{Kesimpulan}

Berdasarkan hasil penelitian, maka dapat disimpulkan beberapa hal, antara lain sebagai berikut:

a) Calon whistleblower di instansi Direktorat Jenderal Pajak, terutama di KPP Pratama tempat dilakukannya penelitian melihat keseriusan pelanggaran sebagai aspek yang perlu dipertimbangkan sebelum melakukan whistleblowing. Jika pelanggaran (fraud atau wrongdoing) yang terjadi memiliki dampak yang sangat besar dan memungkinkan terjadinya kerugian yang signifikan, maka semakin besar pula niat mereka untuk melakukan whistleblowing guna menghentikan atau mencegah kerugian yang lebih besar;

b) Responden penelitian tidak melihat status pelanggar sebagai faktor yang perlu diperhitungkan dalam melakukan whistleblowing. Hal ini dikarenakan adanya rasa aman yang diberikan oleh sistem whistleblowing pada instansi Direktorat Jenderal Pajak; dan

c) Responden dengan tingkat kolektivisme yang tinggi memiliki niat yang lebih besar dalam melakukan whistleblowing. Kesimpulan ini berbeda dengan hasilhasil penelitian sebelumnya.

Secara umum satu-satunya kendala yang dihadapi oleh peneliti dalam penelitian ini adalah waktu. Waktu penelitian bertepatan dengan program tax amnesty dan waktu pelaporan SPT Badan. Implikasinya waktu dilakukannya penelitian dan pengembalian kuisioner melebihi prediksi awal peneliti dan memakan cukup 
banyak waktu. Peneliti selanjutnya mungkin dapat meneliti lebih jauh mengenai orientasi budaya yang memberikan bukti empiris yang berbeda dengan peneliti sebelumnya, sehingga peneliti selanjutnya dapat memberikan konfirmasi atas penelitian sebelumnya dan penelitian saat ini. Peneliti selanjutnya juga bisa menambahkan variabel komitmen organisasional dan budaya organisasi untuk melihat tidak hanya pengaruh dari orientasi budaya yang bersifat bawaan dari individu tapi juga budaya di luar individu yang mungkin memunculkan motivasi lain bagi calon whistleblower untuk melakukan pelaporan (whistleblowing).

\section{Daftar Pustaka}

Ahmad, S. A. 2011. Internal Auditors and Internal Whistleblowing Intentions: A Study of Organisational, Individual, Situational and Demographic Factors. Disertasi Doktoral Akuntansi, Fakultas Bisnis dan Hukum, Universitas Edith Cowan, Australia Barat.

Laporan Tahunan Direktorat Jenderal Pajak. 2015. Diakses 28 Februari 2017, dari http://www.pajak.go.id/content/laporantahunan-djp-2015.

Association of Certified Fraud Examiners. 2014a. Report to the Nation on Occupational Fraud and Abuse. http://www.acfe.com, diakses 28 November 2015.

2014b. The Cost of Fraud. http://www.acfe.com, diakses 28 November 2015.

Ayers, S., dan Kaplan, S. E. 2005. Wrongdoing by Consultants: An Examination of Employees' Reporting Intentions. Journal of Business Ethics 57: 121-137.

Brief, A. P., dan Motowidlo, S. J. 1986. Prosocial Organizational Behaviors. The Academy of Management Review 11(4): 710-725.

Cassematis, P. G., dan Wortley, R. 2013. Prediction of Whistleblowing or Non-reporting Observation: The Role of Personal and Situational Factors. Journal of Business Ethics 117: 615-634.

Chiu, R. K. 2002. Ethical Judgment, Locus of Control, and Whistleblowing Intention: A Case Study of Mainland Chinese MBA Students. Journal of Business Ethics 43(1): 65-74.

Dozier, J. B., dan Miceli, M. P. 1985. Potential Predictors of Whistle-Blowing: A Prosocial Behavior Perspective. Academy of Management Review 10(4): 823-836.

Eisenberg, N., dan Mussen, P. H. 1989. The Roots of Prosocial Behavior in Children. Cambridge University Press.

Gao, J., Greenberg, R., dan Wong-On-Wing, B. 2015. Whistleblowing Intentions of Lower-Level
Employees: The Effect of Reporting Channel, Bystanders, and Wrongdoer Power Status. Journal of Business Ethics 126:85-99.

Gray, S. J. 1988. Towards a Theory of Cultural Influence on the Development of Accounting Systems Internationally. Abacus 24: 1-15.

Hair, J. F., Hult, G. T. M., Ringle, C. M., dan Sarstedt, M. 2014. A Primer on Partial Least Squares Structural Equation Modeling (PLS-SEM). SAGE Publications. United States of America.

Hofstede, G. 1985. The Interaction between National and Organizational Value Systems[1]. Journal of Management Studies 22(4): 347-357.

Irianto, G., Novianti, N., Rosalina, K., dan Firmanto, Y. 2012. Integrity, Unethical Behavior, and Tendency of Fraud. Ekuitas: Jurnal Ekonomi dan Keuangan 16(2): 144-163.

Keenan, J. P. 2002a. Whistleblowing: A Study of Managerial Differences. Employee Responsibilities and Rights Journal 12(4): 17-32.

Keenan, J. P. 2002b. Comparing Indian and American Managers on Whistleblowing. Employee Responsibilities and Rights Journal 14(2-3): 7989.

Keenan, J. P. 2007. Comparing Chinese and American Managers on Whistleblowing. Employ Respons Rights Journal 19: 85-94.

MacNab, B., Brislin, R., Worthley, R., Galperin, B. L., Jenner, S., Lituchy, T. R., MacLean, J., Aguilera, G. M., Ravlin, E., Tiessen, J. H., Bess, D., dan Turcotte, M. 2007. Culture and Ethics Management Whistle-blowing and Internal Reporting within a NAFTA Country Context. International Journal of Cross Cultural Management 7(1): 5-28.

MacNab, B. R., dan Worthley, R. 2008. Self-Efficacy as an Intrapersonal Predictor for Internal Whistleblowing: A US and Canada Examination. Journal of Business Ethics 79: 407-421.

Mesmer-Magnus, J. R., dan Viswesvaran, C. 2005. Whistleblowing in Organizations: An Examination of Correlates of Whistleblowing Intentions, Actions, and Retaliation. Journal of Business Ethics 62: 277-297.

Miceli, M. P., dan Near, J. P. 1988. Individual and Situational Correlates of Whistleblowing. Personnel Psychology 41(2): 267-281.

Miceli, M. P., Near, J. P., dan Schwenk, C. R. 1991. Who Blows The Whistle and Why?. International and Labor Relations Review 45(1): 113-130.

Nayir, D. Z., dan Herzig, C. 2012. Value Orientations as Determinants of Preference for External and Anonymous Whistleblowing. Journal of Business Ethics 107: 197-213. 
Near, J. P., dan Miceli, M. P. 1985. Organizational Dissidence: The Case of Whistleblowing. Journal of Business Ethics 4(1): 1-16.

Near, J. P., Rehg, M. T., Scotter, J. R. V., dan Miceli, M. P. 2004. Does Type of Wrongdoing Affect the Whistle-Blowing Process? Business Ethics Quarterly 14(2): 219-242.

Park, H., Blenkinsopp, J., Oktem, M. K., dan Omurgonulsen, U. 2008. Cultural Orientation and Attitudes Toward Different Forms of Whistleblowing: A Comparison of South Korea, Turkey, and the U.K. Journal of Business Ethics 82: 929-939.

Park, H., Rehg, M. T., dan Lee, D. 2005. The Influence of Confucian Ethics and Collectivism on Whistleblowing Intentions: A Study of South Korean Public Employees. Journal of Business Ethics 58: 387-403.

Reckers-Sauciuc, A. K., dan Lowe, D. J. 2010. The Influence of Dispositional Affect on WhistleBlowing. Advances in Accounting, incorporating Advances in International Accounting 26: 259269.

Republik Indonesia. 2011. Peraturan Direktur Jenderal Pajak Nomor 22/PJ/2011 tentang Kewajiban Melaporkan Pelanggaran dan Penanganan Pelaporan Pelanggaran (Whistleblowing) di Lingkungan Direktorat Jenderal Pajak.

Robinson, S. N., Robertson, J. C., dan Curtis, M. B. 2012. The Effects of Contextual and Wrongdoing Attributes on Organizational Employees' Whistleblowing Intentions Following Fraud. Journal of Business Ethics 106:213-227.

Semendawai, A. H., Santoso, F., Wagiman, W., Omas, B. I., Susilaningtias, dan Wiryawan, S. M. 2011. Memahami Whistleblower. Lembaga Perlindungan Saksi dan Korban (LPSK): Jakarta Pusat.

Septianti, W. 2013. Pengaruh Faktor Organisasional, Individual, Situasional, Dan Demografis Terhadap Niat Melakukan Whistleblowing Internal. Simposium Nasional Akuntansi XVI, Manado.

Sholihin, M., dan Ratmono, D. 2013. Analisis SEM-PLS dengan WarpPLS 3.0. ANDI. Yogyakarta.

Taylor, E. Z., dan Curtis, M. B. 2010. An Examination of the Layers of Workplace Influences in Ethical Judgments: Whistleblowing Likelihood and Perseverance in Public Accounting. Journal of Business Ethics 92: 21-37.

Transparency International. 2014. Corruption Perception Index. https://www.transparency.org, diakses 29 November 2015.

Trongmateerut, P., dan Sweeney, J. T. 2013. The Influence of Subjective Norms on Whistle-
Blowing: A Cross-Cultural Investigation. Journal of Business Ethics 112: 437-451.

Winardi, R. D. 2013. The Influence of Individual and Situational Factors on Lower-Level Civil Servants' Whistle-Blowing Intention in Indonesia. Journal of Indonesian Economy and Business 28(3): 361-376.

Zhang, J., Chiu, R., dan Wei, L. 2009. Decision-Making Process of Internal Whistleblowing Behavior in China: Empirical Evidence and Implications. Journal of Business Ethics 88:25-41.

Zhuang, J. 2003. Whistle-blowing dan Peer Reporting: A Cross-cultural Comparison of Canadians and Chinese. Tesis Magister Ilmu Manajemen, Fakultas Manajemen, Universitas Lethbridge, Lethbridge, Alberta, Kanada. 